\title{
Chinese Aid to Africa: Distinguishing Features and Local Effects
}

The global economic landscape has changed dramatically since the turn of the millennium: low and middle income countries have been driving global economic growth, new sources of development finance have emerged, and the development cooperation arena has seen continued diversification of actors, instruments, and delivery mechanisms (Kharas and Rogerson 2012; Mawdsley et al. 2014). Largest among the "new" donors is China, and with the explosion of Chinese funds, concerns over its donor practices have followed.

Critics claim that Beijing uses its development finance to create alliances with the leaders of developing countries, to secure commercial advantages for their domestic firms, and to prop up corrupt and undemocratic regimes in order to gain access to their natural resource endowments (see the discussion in e.g., Tull 2006; Naím 2007; Penhelt 2007; Brazys et al. 2017). Others praise China for its responsiveness to recipient needs and its ability to get things done in a timely manner without placing an extensive administrative burden on strained public bureaucracies in the developing world (see the discussion in e.g., Bräutigam 2009; Dreher et al. 2019).

In the 2018 Forum on China-Africa Cooperation, China made a USD 60 billion pledge for new projects in Africa (Washington Post 2018). Despite its massive scale, studying the motivations behind and effects of Chinese development finance has, until recently, been very difficult. Unlike the OECD-DAC donors, the Chinese government does not routinely publish information on its foreign assistance. This lack of transparency has made evaluation of Chinese aid notoriously difficult, and as a result, China's aid to Africa is the subject of much speculation. However, with a new comprehensive dataset on Chinese Official Finance to Africa issued by the AidData research laboratory (AidData 2017), systematic quantitative analysis of Chinese aid flows is now possible.

This article draws on our recent work on Chinese development finance to Africa. We highlight a number of distinguishing features of Chinese aid, and how these may translate into local aid impacts that differ from those of other donors. In particular, we discuss the arguments and findings in Isaksson and Kotsadam (2018a, 2018b), Isaksson (2019), and Knutsen and Kotsadam (2020). In these studies, we geographically match the new geo-referenced dataset on the subnational allocation of Chinese development finance projects to Africa with comprehensive survey data for a broad range of African countries, and evaluate the local effects of Chinese aid on corruption, trade union involvement, ethnic identities, and incumbency support, respectively.

\section{DISTINGUISHING FEATURES OF CHINESE AID}

A number of features make Chinese aid stand out from that of western donors. First, China is well-known for its policy of non-interference in the domestic affairs of recipient countries (see e.g., Tull 2006; Bräutigam 2009). The principle is explicitly spelled out in official Chinese documents: "When providing foreign assistance, China adheres to the principles of not imposing any political conditions, not interfering in the internal affairs of the recipient countries, and fully respecting their right to independently choosing their own paths and models of development" (State Council 2014). While recipient country governments tend to see the principle as a sign of China respecting their countries' sovereignty, critics view it as a convenient rationale for economic involvement in undemocratic and corrupt regimes and suggest that it makes Chinese aid easy to exploit for politicians.

Second, Chinese development finance tends to mix commercial interests with concessional flows (see e.g., Tull 2006; Bräutigam 2009). As with the non-interference principle, China explicitly states that its development policy should result in a win-win situation for both sides (Tull 2006). The blurring of concessional finance with other financial flows means that it is difficult to distinguish between China's commercial interests and transfers with a development intent; their projects tend to contain elements of both.

Next, the Chinese aid allocation process tends to be demand driven (see e.g., Brautigam 2011). As described in detail in Dreher et al. (2019), China's aid allocation is often based on requests from recipientcountry governments. Its aid packages and projects tend to be negotiated in high-level meetings with political leaders rather than publicly outlined in country

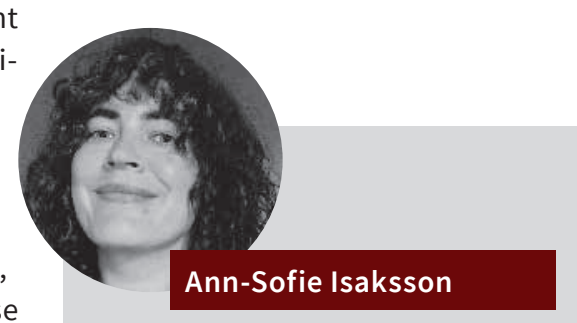

is Associate Professor at the University of Gothenburg and Researcher at the IFN-Research Institute of Industrial Economics, Stockholm.

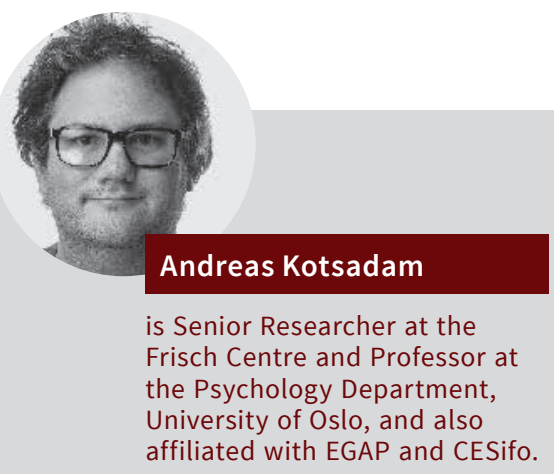


development assistance strategies, with the initiative generally coming from the recipient side. Interpreted favorably, this could again be seen as a sign of ensuring partner country ownership of development policy. At the same time, however, a request-based system of aid project delivery may provide opportunities for recipient country governments to use funds strategically by promoting a subnational distribution of funds that favors their patronage network.

Finally, China stands out in terms of its degree of control over aid project implementation. Unlike other donors that often use local implementing agencies, China tends to maintain control over the projects it funds from the project initiation phase to the project completion phase, often using Chinese contractors for work performed in the recipient countries (see e.g., Bräutigam 2009).

\section{POSSIBLE EMPIRICAL IMPLICATIONS}

In light of these distinguishing features of Chinese development finance, the studies reviewed in this article explore whether the local effects of Chinese aid stand out from those of other donors.

In one study (Isaksson and Kotsadam 2018a), we investigate whether Chinese development projects affect local corruption in Africa. A potential effect could work both via economic incentives, i.e., through the presence of donors affecting the costs and benefits of engaging in corrupt activity, and by means of norm transmission. Two of the above features of Chinese aid are particularly relevant in this respect. First, China's policy of non-interference in the domestic affairs of recipient countries suggests that it is unlikely to take an active role in fighting corruption in the same. Unlike donors with a clear anti-corruption policy, such as the World Bank, it thus seems unlikely that the Chinese presence should involve increased monitoring and delegitimization of corrupt practices. Second, and conversely, considering reports of corruption among Chinese firms operating abroad (Transparency International, 2011), its tendency to maintain control over development projects throughout the entire implementation phase implies that Chinese development projects may stand out in terms of the use of corrupt practices. The Chinese presence could thus affect descriptive corruption norms for the worse.

In another study, we examine the impact of Chinese development projects on labor union involvement in African recipient countries (Isaksson and Kotsadam 2018b). Anecdotal evidence points to violations of international labor standards at Chinese investment sites in Africa (e.g., Human Rights Watch 2011; and Akorsu and Cooke 2011). Again, the distinguishing features of Chinese development finance are relevant to consider. Since China tends to maintain control over development projects throughout the implementation phase, its presence could reasonably exert an influence on local labor market institutions.
Considering that Chinese firms have little tradition of unions and organized labor at home (ITUC 2010), this could mean that Chinese labor relations are transplanted to the recipient countries. Furthermore, and related, the fact that Chinese development finance tends to mix commercial interests with concessional flows likely implies that cost cutting, e.g., with respect to labor expenses, is an important dimension at the project implementation phase.

Based partly on the results from these previous studies, we also examine the effects of aid on incumbency support at the local level (Knutsen and Kotsadam 2020). If aid affects corruption, unionization, and local economic conditions differently it is reasonable to expect that it also affects incumbency advantage differently. If aid has overall positive effects at the local level, voters may reward incumbent leaders who locate aid to their area. Aid may also lead to lower support for the incumbent leader if it has negative effects at the local level or undermines the capacity and legitimacy of recipient governments. One can also expect Chinese aid to be different with respect to incumbency effects due to the stated non-interference of Chinese aid in combination with its demand driven nature.

Our most recent study explores whether Chinese development projects fuel local ethnic identities in African recipient countries (Isaksson 2019). In line with the findings of Eifert et al. (2010), who find that ethnic identities are mobilized in the struggle for political power and economic resources, competition for the inflow of resources that aid constitutes could mobilize ethnic identities across the board. A second possible mechanism, in line with a "reactive ethnicity" approach (Çelik 2015), is that perceived ethnic bias in the delivery of aid gives rise to ethnic grievances, and thereby more salient ethnic identities, in groups that perceive themselves as disadvantaged. Recent empirical evidence suggests that Chinese aid may be particularly easy to exploit for politicians who are engaged in patronage politics (Dreher et al. 2019). Both the demand-driven nature of the Chinese aid allocation process and China's policy of non-interference in the domestic affairs of partner countries arguably make Chinese development funds prone to elite capture, and thus to possible ethnic bias. The next section provides an account of how we evaluate these questions empirically.

\section{DATA AND EMPIRICAL STRATEGY}

To explore the local effects of Chinese development projects in Africa, we geographically match spatial data on China's official financial flows to the continent over the period 2000-2012 with Afrobarometer survey data for a large sample of respondents from a broad range of African countries. ${ }^{1}$ The data on Chi-

1 In the corruption paper, 98,449 respondents from 4 Afrobarometer survey waves in 29 African countries; in the trade union paper, 
nese aid projects is obtained from geo-referenced project-level data of AidData's Geocoded Global Chinese Official Finance Version 1.1.1 dataset (AidData 2017). Since the Chinese government does not release official, project-level financial information about its foreign aid activities, this data is based on an opensource media-based data collection technique, synthesizing and standardizing a large amount of information on Chinese development finance to African countries (described in detail in Strange et al. 2015). The coordinates of the surveyed Afrobarometer clusters are used to match individuals to aid project sites with precise point coordinates. We measure the distance from the cluster center points to the aid project sites and identify the clusters located within a cut-off distance - e.g., $50 \mathrm{~km}$ - of at least one project site.

Since the distribution of aid within countries is not random - implying that some individuals and sub-national areas, with certain characteristics, will be more likely than others to be targeted by aid - we use a spatial-temporal estimation strategy resembling that in Knutsen et al. (2017). While the fact that the Afrobarometer is not a panel hinders us from following specific localities over time, before and after a project was initiated, with this estimation strategy we can still make use of the time variation in the data. In particular, we compare the estimated effect of living near sites where a Chinese development project is currently under implementation with the estimated effect of living near sites where a project will be opened but where implementation had not yet been initiated at the time the Afrobarometer covered that particular area. The baseline regression takes the form:

(1) $Y_{i v t}=\beta_{1} \cdot$ Ongoing $_{i t}+\beta_{2} \cdot$ Future $_{i t}+\alpha_{s}+\delta_{t}+\gamma \cdot \mathbf{X}_{i t}+\varepsilon_{i v t}$

where the outcome variable $Y$ for an individual $i$ in cluster $v$ at year $t$ is regressed - in the benchmark setup using linear probability models - on a dummy variable Ongoing capturing whether the individual lives within the specified cut-off distance of an ongoing Chinese development project, and a dummy Future for living close to a site where a Chinese project is planned but not yet implemented at the time of the survey (those with no Chinese project site within the cut-off distance are the omitted reference category). The regressions include spatial (country or sub-national region) fixed effects $\left(\alpha_{s}\right)$ and year fixed effects $\left(\delta_{t}\right)$, and a vector $\left(\mathrm{X}_{i}\right)$ of individual-level controls (age, age squared, gender, and urban/rural residence). The standard errors are clustered at the geographical clusters.

The coefficient on Ongoing $\left(\beta_{1}\right)$ captures any causal effect of aid plus potential selection effects. The

41,902 respondents from 18 African countries obtained from rounds 2 and 3 of the Afrobarometer survey; in the incumbency paper,

101,792 from 5 rounds; and in the ethnic identities paper, 50,527 res pondents from 11 African countries obtained from rounds 3-6 of the Afrobarometer survey. coefficient on Future $\left(\beta_{2}\right)$, on the other hand, captures only a selection effect, as the concerned aid projects had not yet started at the time of the survey and so cannot have had a causal effect. The idea is that by taking the difference between these two parameters, we subtract the selection effect from the combined selection and causal effect, leaving behind the causal effect of aid on the outcome variable in focus. The parameter difference between Ongoing and Future $\left(\beta_{1}-\beta_{2}\right)$ thus gives a difference-in-difference type of measure that controls for unobservable time-invariant characteristics that may influence selection into being a Chinese project site. The key assumption behind this approach is that the selection process relevant for ongoing and future projects sites is the same. We evaluate this assumption in a range of robustness tests. The incumbency paper uses a different approach, whereby area fixed effects are added so that the coefficient on Ongoing captures differences only in areas before and after aid projects start.

\section{EMPIRICAL FINDINGS}

Figure 1 provides a brief summary of the main empirical findings. ${ }^{2}$ It shows the parameter difference between ongoing and future from estimations like that in equation (1), with citizen experiences with corruption, union involvement, and ethnic identities as the respective dependent variables. ${ }^{3}$

To begin with, the results consistently indicate that Chinese aid projects fuel localcorruption. Respondents with an ongoing rather than a future Chinese project within $50 \mathrm{~km}$ are, for instance, significantly more likely to report that they have been asked for a bribe when dealing with the police. Investigating possible underlying theoretical mechanisms, the effect does not appear to be driven simply by an increase in economic activity. Rather, suggestive evidence seems to indicate that the Chinese presence

2 As Knutsen and Kotsadam (2020) employ a different estimation strategy, we do not include the estimates in this figure.

3 For detailed results, sensitivity estimations, and comparisons with other donors, see the original studies.

\section{Figure 1}

Local Effects of Chinese Aid

Summary of empirical findings

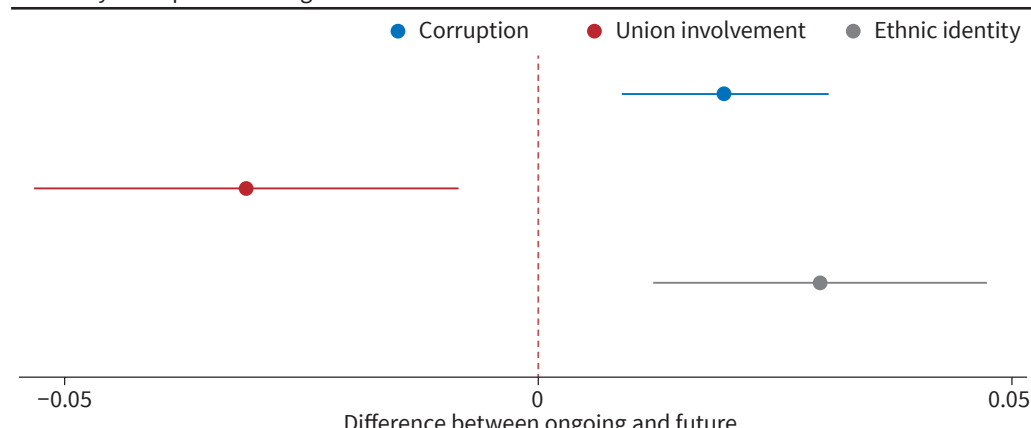

Note: Figure shows the parameter difference between ongoing and future from estimations similar to equation (1), with citizen experiences with corruption, union involvement, and ethnic identities as the respective dependent variables. Source: Isaksson and Kotsadam (2020).
( ifo Institute 
impacts local norms. Running equivalent estimations for World Bank aid projects, for which there is also geo-referenced data available for a large multi-country African sample, the estimations provide no consistent evidence of a corresponding increase in local corruption around project sites. In particular, whereas the results indicate that Chinese aid projects fuel local corruption but have no observable impact on local economic activity, they suggest that World Bank aid projects stimulate local economic activity without any consistent evidence of it fueling local corruption.

Also in line with predictions, the results suggest that Chinese development projects discourage trade union involvement in the surrounding areas. These results do not translate to other forms of citizen participation not directly connected to the workplace, seemingly indicating that the lower unionization rates observed near ongoing as compared to future Chinese project sites stem from direct anti-union policies rather than from more general institutional change. Again, China clearly diverges from other donors in this respect. In particular, in line with World Bank efforts to promote civil society development and community participation, World Bank projects are found to stimulate rather than to discourage union involvement.

Based on the previous findings it is interesting to see whether the effects on incumbency support also differ for Chinese aid versus aid from other donors. Knutsen and Kotsadam (2020) find that aid from the World Bank increases incumbency support whereas there is no robust evidence that this is the case for Chinese aid. A possible explanation for the differential impact of aid on incumbency support is the negative effects described above. In addition, we find that aid from the World Bank increases trust in politicians whereas we do not find an effect for Chinese aid.

Finally, the empirical results indeed suggest that living near an ongoing Chinese project makes ethnic identities more salient. The effect is not uniform though, but driven by people who belong to the outgroup - i.e., who are not co-ethnics of the country president at the time - arguably signaling that it is driven by ethnic grievances originating in perceived ethnic bias rather than ethnic competition for resources more generally. Furthermore, a comparison across donors reveals that Chinese development projects stand out from those of other influential donors in this respect. Replicating the key analysis for World Bank projects, the results in fact indicate the reverse, i.e., that living near an ongoing as opposed to a future project comes with weaker ethnic identification. This too seemingly speaks against the general ethnic competition mechanism.

\section{CONCLUSIONS}

This article drew on our recent work on local effects of Chinese development projects in Africa. We high- lighted a number of distinguishing features of Chinese aid - its non-interference principle, its tendency to mix commercial interests with concessional flows, the demand driven aid allocation process, and its control over projects throughout the implementation phase - and discussed how these may translate into local aid impacts that differ from those of other donors.

Our empirical findings indeed indicated that important local effects of Chinese aid stand out from those of other donors. Unlike aid from other major donors, Chinese aid projects were found to fuel local corruption, discourage trade union involvement, to not increase political incumbency support, and to make ethnic identities more salient in the local areas. As such, our findings highlight important donor heterogeneities as well as the need to consider not only to what extent aid achieves its explicit objectives, but also its potential unintended effects, or externalities.

\section{REFERENCES}

AidData Research and Evaluation Unit (2017), Geocoding Methodology, Version 2.0., Williamsburg, VA: AidData at William \& Mary, https://www.aiddata.org/publications/geocoding-methodology-version-2-0 (accessed April 15, 2020).

Akorsu, D. A. and F. L. Cooke (2011), "Labour Standards Application among Chinese and Indian Firms in Ghana: Typical or Atypical?," The International Journal of Human Resource Management, 22(13), 2730-2748.

Brautigam, D. (2009), The Dragon's Gift: The Real Story of China in Africa, Oxford, UK: Oxford University Press.

Brautigam, D. (2011), “Aid 'with Chinese Characteristics': Chinese Foreign Aid and Development Finance Meet the Oecd-Dac Aid Regime," Journal of International Development, vol. 23, pp. 752-764.

Brazys, S., J.A. Elkink, and G. Kelly (2017), "Bad Neighbors? How Co-located Chinese and World Bank Development Projects Impact Local Corruption in Tanzania," The Review of International Organizations, 12(2), 227-253.

Celik, C. (2015), “Having a German Passport will not make me German': Reactive Ethnicity and Oppositional Identity among Disadvantaged Male Turkish Second-Generation Youth in Germany," Ethnic and Racial Studies, 38:9, 1646-1662.

Dreher, A., A. Fuchs, R. Hodler, B.C. Parks, P.A. Raschky, and M.J. Tierney (2019), "African Leaders and the Geography of China's Foreign Assistance," Journal of Development Economics, 140, 44-71.

Eifert, B., E. Miguel, and D. N. Posner (2010), "Political Competition and Ethnic Identification in Africa," American Journal of Political Science, 54(2), 494-510.

Human Rights Watch (2011), "'You'll Be Fired if You Refuse' Labour Abuses in Zambia's Chinese State-Owned Copper Mines," Human Rights Watch, November 2011.

Isaksson, A. and A. Kotsadam (2018a), "Chinese Aid and Local Corruption,” Journal of Public Economics, vol. 159, 146-159.

Isaksson, A. and A. Kotsadam (2018b), "Racing to the Bottom? Chinese Development Projects and Trade Union Involvement in Africa," World Development, vol. 106, 284-298.

Isaksson, A. (2019), "Chinese Aid and Local Ethnic Identification," Working Papers in Economics no. 761, University of Gothenburg, Department of Economics.

ITUC (2010), "Internationally Recognised Core Labour Standards in the People's Republic of China," International Trade Union Confederation (ITUC), Report for the WTO General Council Review of the Trade Policies of the People's Republic of China, Geneva May 2010.

Kharas, H. and A. Rogerson (2012), "Horizon 2025: Creative Destruction in the Aid Industry," Overseas Development Institute, July 2012.

Knutsen, C. H., A. Kotsadam, H. Olsen, and T. Wig (2017), "Mining and Local Corruption in Africa," forthcoming in American Journal of Political Science, 61(2), 320-334. 
Knutsen, T. and A. Kotsadam (2020), "The Political Economy of Aid Allocation: Aid and Incumbency at the Local Level in Sub-Saharan Africa," World Development, 127, 104729.

Mawdsley, E., L. Savage, and K. Sung-Mi (2014), "A 'Post-aid World'? Paradigm Shift in Foreign Aid and Development Cooperation at the 201 Busan High Level Forum," The Geographical Journal, 27-38.

Naím, M (2007) "Rogue Aid," Foreign Policy, No. 159, March/April 2007.

Pehnelt, G. (2007), "The Political Economy of China's Aid Policy in Africa," Jena Economic Research Papers no. 051. University of Jena, Germany, https://papers.ssrn.com/sol3/papers.cfm?abstract_id=1022868 (accessed May 8, 2020).

State Council (2014), "White Paper on China's Foreign Aid," Information Office of the State Council, The People's Republic of China, July 2014 Beijing, http://english.gov.cn/archive/white_paper/2014/08/23/cont-

ent_281474982986592.htm (accessed March 2020)
Strange, A. M., B. Parks, M.J. Tierney, A. Fuchs, and A. Dreher (2015),

"Tracking Under-reported Financial Flows: China's Development Finance and the Aid-Conflict Nexus Revisited," Journal of Conflict Resolution, $1-29$.

Transparency International (2011), "Bribe Payers Index 2011,"

https://issuu.com/transparencyinternational/docs/bribe_payers_in dex_2011?mode=window\&backgroundColor=\%23222222 (accessed March 2020).

Tull, D. M. (2006), "China's Engagement in Africa: Scope, Significance and Consequences," Journal of Modern African Studies, 44(3), 459-479.

Washington Post (2018), "Xi Jinping Pledged \$60 Billion for Africa. Where will the Money Go?," L. Benabdallah and W. Robertson, The Washington Post, September 17, 2018. 